\title{
TAXI TIME VARIATION AT MAJOR U.S. AIRPORTS
}

\author{
Derek P. Robinson and Daniel J. Murphy, Federal Aviation Administration, Washington, DC
}

\section{Abstract}

The objective of this study was to investigate aircraft taxi times at major U.S. airports. The authors of this investigation previously published a novel, statistical approach to characterizing taxi behavior. In that approach, we attempted to separate deterministic effects, such as departure queuing delays, from variations we asserted analysts could treat as noise. We produced a methodology for creating taxi time parameters for a known combination of airport, carrier, and equipment type. Analysts could use those parameters to simulate taxi times in NAS-wide models. We acknowledged that runway assignment introduced variation in taxi times that would be improper to consider noise. However, we resigned ourselves to ignoring runway assignment because runway data was not easily available. Additionally, we asserted analysts could ascertain a sufficient airport location from the aircraft's carrier and the equipment type. In this investigation, we continued those efforts. We used a similar approach to determine parameters suitable for describing taxi behavior by a particular aircraft, at a particular airport. However, in this investigation, we included some of those factors that we previously ignored. This time, we used the airport runway and the airport gate to help determine appropriate taxi time parameters. We demonstrated the benefits from using the increased information. The additional information used to determine taxi time parameters decreased the variation to the underlying taxi time distribution. However, the improved taxi time parameters yielded mix benefits regarding delay. Runway assignment proved very beneficial to improved delay calculations. However, airport gate only translated into a minimal benefit.

\section{Introduction}

The FAA Modernization and Reform Act of 2012 requires the Federal Aviation Administration (FAA) to monitor air carriers' scheduled operations. The act then requires the FAA to take action if they expect those operations will have "a significant adverse effect on the safe and efficient use of navigable airspace." Hence, the FAA's Office of
Performance Analysis generates a monthly report that identifies airports projected to have chronic delay within the subsequent six-month period. During fiscal year (FY) 2011, 1 October 2010 to 30 September 2011, air carriers scheduled operations at 675 domestic airports. The FAA's Office of Performance Analysis analyzes operations involving each of those airports. However, to keep the report succinct, the FAA's Office of Performance Analysis limits the monthly report to thirty major U.S. airports (Core 30 airports) ${ }^{1}$. This reporting limit does not compromise the integrity of the report because almost $90 \%$ of FY 2011 National Airspace System (NAS) scheduled operations involved at least one Core 30 airport [1].

The FAA's Office of Performance Analysis uses a variety of models to project the delay at the Core 30 airports. To simulate reality, the models must properly account for each segment of the aircraft's operation and the delay associated with each segment. Capacity limitations, such as those caused by a limited number of runways or congested airspace, primarily cause delays in the real system. However, to keep the problem tractable, many NASwide models exclude some features. In particular, many system-wide models omit the surface structure at airports, which includes a complex network of taxiways and runways.

\footnotetext{
1 The Core 30 Airports are Hartsfield-Jackson Atlanta International (ATL), Boston Logan International (BOS), Baltimore/Washington International (BWI), Charlotte/Douglass International (CLT), Ronald Regan Washington National (DCA), Denver International (DEN), Dallas/Fort Worth International (DFW), Detroit Metropolitan Wayne County (DTW), Newark Liberty International (EWR), Ft. Lauderdale-Hollywood International (FLL), Honolulu International (HNL), Washington Dulles International (IAD), Houston George Bush Intercontinental (IAH), New York John F. Kennedy International (JFK), Las Vegas McCarran International (LAS), Los Angeles International (LAX), New York La Guardia (LGA), Orlando International (MCO), Chicago Midway International (MDW), Memphis International (MEM), Miami International (MIA), Minneapolis-St. Paul International (MSP), Chicago O'Hare International (ORD), Philadelphia International (PHL), Phoenix Sky Harbor International (PHX), San Diego InternationalLindbergh Field (SAN), Seattle-Tacoma International (SEA), San Francisco International (SFO), Salt Lake City International (SLC), and Tampa International (TPA).
} 
The FAA recognizes the importance of airport surface structures in maintaining an efficient flow of aircraft throughout the NAS. For some aircraft operations, the time spent on the airport surface accounts for a significant portion of that aircraft's gate-to-gate time. Hence, the FAA's future goal of an efficient and predictable aviation system with increased capacity includes a performance metric of reducing the average taxi time at Core airports. To achieve this portion of the goal, the FAA monitors aircraft taxi time and delay [2].

In a previous paper, the authors proposed using a novel statistical approach to characterize taxi behavior. We attempted to separate deterministic effects, such as departure queuing delays, from variations we asserted analysts could treat as normally distributed noise. We produced a methodology for creating taxi time parameters for a known combination of airport, carrier, and equipment type. Analysts could use those parameters to simulate taxi times in NAS-wide models. We acknowledged limitations to our data as well as to our assertions. In this investigation, we continue those efforts. We use a similar approach to determine parameters suitable for describing taxi behavior by a particular aircraft, at a particular airport. However, in this investigation, we attempt to quantify the reduction in variance that comes with improved data, namely knowledge of the runway used. We also attempt to determine the validity of our assertion that knowledge of the aircraft's carrier and equipment type provides sufficient knowledge about the aircraft's location. We test this assertion by introducing arrival and departure gate data into our methodology. We further attempt to determine if nominal taxi times based on the additional information changes the perception of average taxi delay at the airports we study [3].

\section{Taxi Time Data}

The U.S. Department of Transportation (DOT) requires U.S. air carriers to report flight performance data if the air carrier meets a revenue threshold for the twelve month period ending in June of the prior year. The DOT uses this data, Airline Service Quality Performance (ASQP) data, to monitor the air carrier's on-time performance and to provide information to consumers. The ASQP dataset includes scheduled and actual flight data for all scheduled nonstop domestic passenger flights operated by the reporting carriers. For calendar year 2011, sixteen carriers ${ }^{2}$ reported ASQP data. Fifteen carriers obligatorily reported and one carrier voluntarily reported [4].

The DOT requires that air carriers report four actual times for a flight: gate departure; wheels-off; wheels-on; and gate arrival. Gate departure occurs when the flight crew has released the parking brake, completed loading passengers, and closed aircraft doors. Wheels-off occurs when the aircraft's landing gear lifts off the runway during departure. Wheels-on occurs when the aircraft's landing gear touches down on the runway during arrival. Gate arrival occurs when the pilot sets parking brake in the passenger unloading area. Using this data, the DOT calculates the taxi-out time, the elapsed time between the gate departure time and the wheels-off time, and the taxiin time, the elapsed time between the wheels-on time and the gate arrival time, for each flight. Some definitions of taxiing only include the aircraft's movement on taxiways and runways. However, the definitions used by the DOT include movement in the airport's ramp area. Consequently, this paper also uses the DOT's definitions [4].

As previously stated, the time an aircraft spends on the airport surface can account for a significant portion of that aircraft's gate-to-gate time. During FY 2011, ASQP flights totaled over 750 million minutes of actual elapsed flight time (gate-to-gate). Aircraft taxied for over 130 million of those minutes (over 90 million taxi-out minutes and over 40 million taxi-in minutes). On average, the total taxi time accounts for about $17 \%$ of the total gate-to-gate flight time. However, most ASQP flights accumulated a larger percentage of surface time. Aircraft traveling less than 750 miles $(60 \%$ of ASQP flights) spent at least $20 \%$ of their gate-to-gate time on an airport surface. Therefore, an inaccurate representation of aircraft taxi times can adversely affect the results produced by a NAS model.

\footnotetext{
${ }^{2}$ In calendar year 2011, the fifteen carriers required to report ASQP data were AirTran Airways, Alaska Airlines, American Airlines, American Eagle Airlines, Atlantic Southeast Airlines, Continental Airlines, Delta Air Lines, Frontier Airlines, Hawaiian Airlines, JetBlue Airways, Mesa Airlines, SkyWest Airlines, Southwest Airlines, United Airlines, and US Airways. The carrier that voluntarily reported ASQP data was ExpressJet Airlines.
} 


\section{Analysis Methodology}

We previously asserted that one could separate the observed distribution of taxi times into an underlying normal distribution and deterministic effects that extend the aircraft's taxi time, such as runway and gate. In Figure 1, we compare a normal distribution to the taxi time distribution of all FY 2011 arrivals. We approximate the mean of the underlying normal distribution by assuming it equals the mode of the observed distribution. We approximate the standard deviation of the underlying distribution by relying on the relationship between the standard deviation of a normal distribution and its width. We calculate the half-width of the left side of the observed distribution at its half maximum (HWHM). We then use that width to determine the standard deviation of the underlying normal distribution. We asserted that aggregating the major factors influencing the taxi time duration (e.g. airport and airport location) explains and reduces the variance of the underlying distribution. We also asserted that one could determine a sufficient airport location from the operating carrier, ticketing carrier, and the equipment type. We offer a more thorough explanation of this methodology in [4].

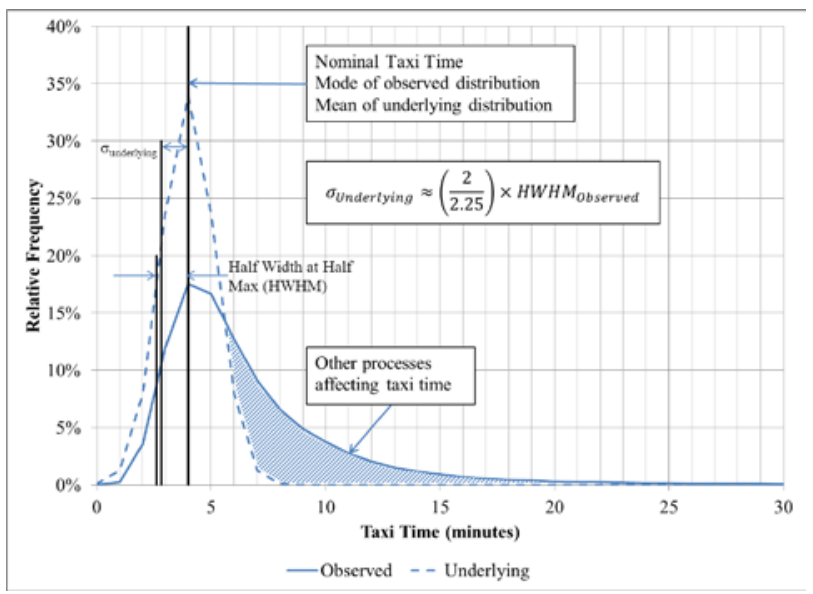

Figure 1. FY 2011 Taxi-In Distributions

\section{Our Methodology Versus ASPM}

Many NAS models and analyses use Aviation System Performance Metrics (ASPM) generated values as a baseline for delay calculations. The ASPM database combines data from different sources for NAS metric calculations. Each flight record in the ASPM database contains actual and nominal taxi times. Using those values, the ASPM database calculates taxi delay. In general, ASPM generates larger nominal taxi times than those generated using our methodology. ASPM uses a similar definition for taxi times as we do. However, their nominal value generation methodology attempts to compute an unimpeded taxi time for a given operation by extrapolating the data to a condition with only one aircraft on the airport surface [5].

During FY 2011, an average ASQP departure taxied for 15.33 minutes, resulting in 4.34 minutes of taxi-out delay measured against ASPM nominal values. Measuring the taxi-out delay against the nominal values developed by the authors reduces the delay to 3.64 minutes. Figure 2 compares FY 2011 average taxi-out delay for ASQP departures for each of the Core 30 airports. For most airports (90\%), the delay values based on ASPM nominal values produce larger average delay. On average, ASPM nominal values suggest that an aircraft experiences about one more minute of delay than those based on the author's methodology. However, the average delay can differ by almost four minutes for an individual airport. Regardless of the method selected, aircraft operating at airports in the New York area experienced the greatest amount of taxi-out delay.

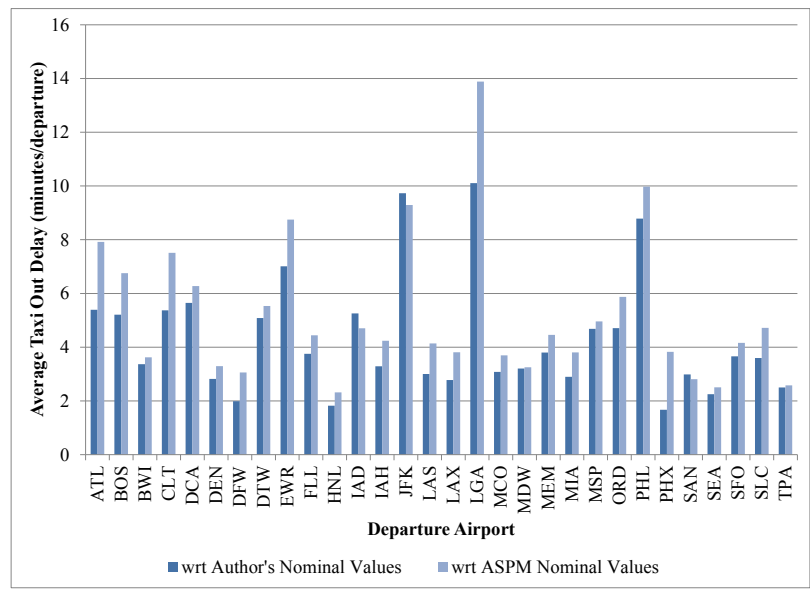

Figure 2. FY 2011 Average Taxi-Out Delay

During FY 2011, an average ASQP arrival taxied for 6.74 minutes, resulting in 1.66 minutes of taxi-in delay measured against ASPM nominal values. Measuring the taxi-in delay against the nominal values developed by the authors reduces the delay to 1.50 minutes. Figure 3 compares FY 2011 average taxi-in delay for ASQP arrivals for each of 
the Core 30 airports. For most airports (77\%), the delay values based on ASPM nominal values produce larger average delay. On average, ASPM nominal values and the author's nominal values suggest that an aircraft experiences similar delay. However, the average delay can differ by almost two minutes for an individual airport.

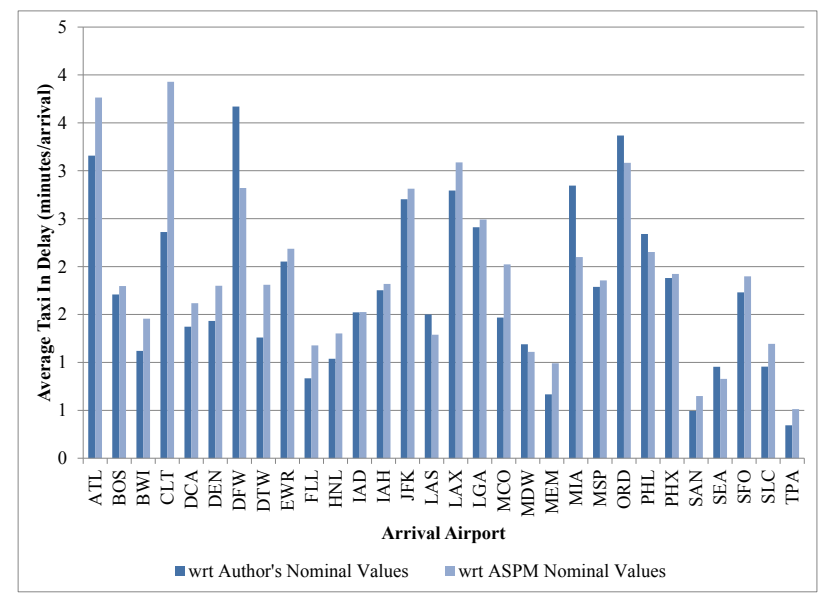

Figure 3. FY 2011 Average Taxi-In Delay

\section{Factors Influencing Taxi Times}

In this section, we investigate some of the assertions and concessions made in the previous publication. We explore the reduction in variance that comes with additional knowledge about the individual departures and arrivals. Using our methodology, we aggregate the departures and arrivals by airport, runway, carrier, concourse/terminal, and gate according to the aggregation levels identified in Figure 4. We then compare the distributions of each aggregation level with the distributions of the previous aggregation level.

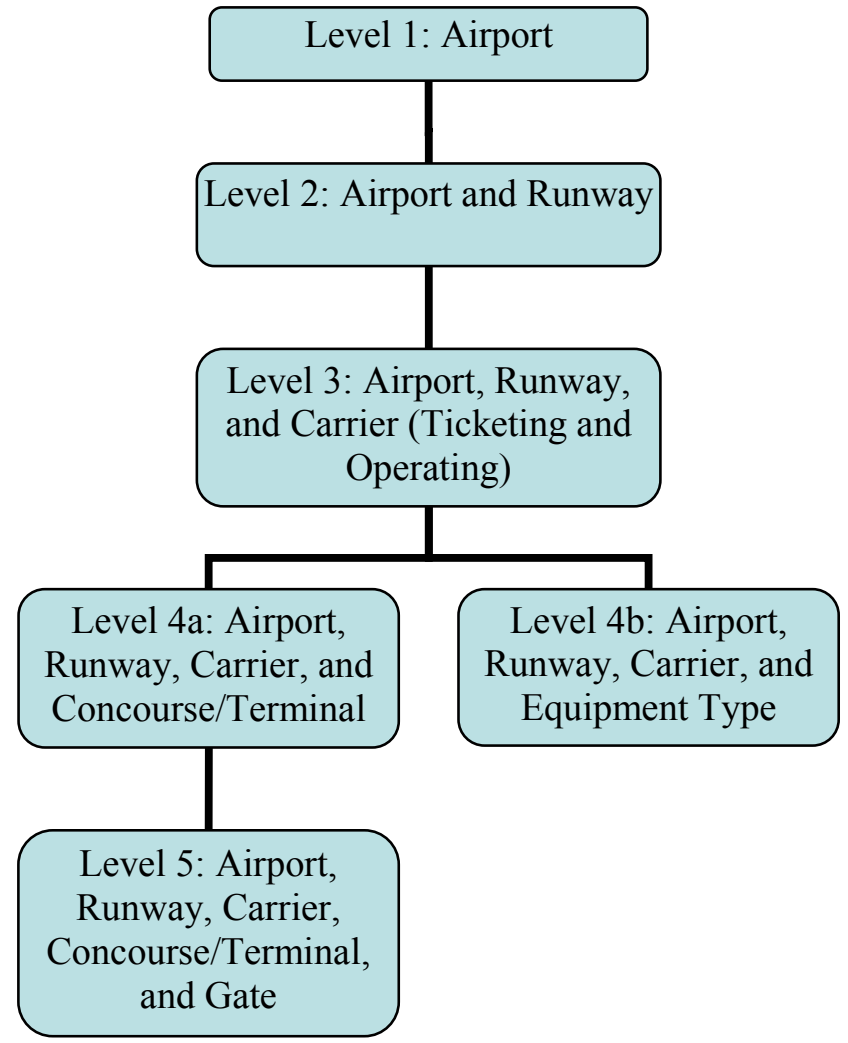

Figure 4. Taxi Time Aggregation Levels

In the previous publication, we primarily used equipment type to help estimate airport gate locations. Carriers configure airport gates to accommodate different sized aircraft. Some equipment types travel different distances during taxiing, resulting in different taxi times. Therefore, we asserted that one could determine an airport location with the aircraft's carrier and the equipment type. For this analysis, we used arrival and departure gate data. Most aircraft types included in this study taxi to and from the runway at similar speeds. Hence, we excluded equipment type when using actual gate data.

If we consider all of the factors that influence taxi times at all airports in the NAS (or even at all Core 30 airports), the number of possible combinations quickly becomes overwhelming. For example, the sixteen operating carriers that reported ASQP departures at Hartsfield-Jackson Atlanta International (ATL) in FY 2011 created eighteen ticketing carrier and operating carrier combinations. They used ten runways for arrival and departure. They also used a significant portion the seven concourses, two terminals, and 200 gates at the 
airport. To keep this portion of the analysis manageable, we only investigate the effects of including these factors at three of the Core 30 airports, ATL, New York John F. Kennedy International (JFK), and Chicago O'Hare International (ORD).

\section{Impact of Runway Assignment on Variance}

To examine the effects of the various factors influencing taxi times, we revisit the relationship between the width of the observed distribution and the standard deviation of the underlying distribution. Our methodology limits the influence of the observed distribution to the observations within the halfmaximum region. Hence, we assert that the closeness of the higher-level distribution's (e.g. including runways) half-maximum region and its corresponding lower-level distribution's (e.g. excluding runway/airport only) half-maximum determines the amount in which the higher-level observations influence the lower-level distribution. We illustrate this assertion in Figure 5 using taxi time distributions for arrivals at ATL aggregated by runway. In Figure $5 \mathrm{a}$, we compare the distribution of arrivals using Runway 26R (higher-level) with the distribution of arrivals using all runways (lower-level). The halfmaximum region of the distribution of all arrivals contains the mode for the distribution of Runway $26 \mathrm{R}$ arrivals. Therefore, we assert that Runway $26 \mathrm{R}$ arrivals make a significant contribution to the standard deviation of the underlying distribution of all runway arrivals. In Figure 5b, we compare the distribution of arrivals using Runway 08L (higherlevel) with the distribution of arrivals using all runways (lower-level). The half-maximum region of the distribution of all arrivals does not contain the mode for the distribution of Runway 08L arrivals, but the half-maximum region for both distributions overlap. Therefore, we assert that Runway 08L arrivals contribute to the standard deviation of the underlying distribution of all runway arrivals. In Figure 5c, we compare the distribution of arrivals using Runway 28 (higher-level) with the distribution of arrivals using all runways (lower-level). The halfmaximum regions are completely separate. Therefore, we assert that Runway 28 arrivals do not contribute to the standard deviation of the underlying distribution of all runway arrivals. Furthermore, we consider the underlying distribution for Runway 28 arrivals and the underlying distribution for all airport arrivals to be completely separate distributions.
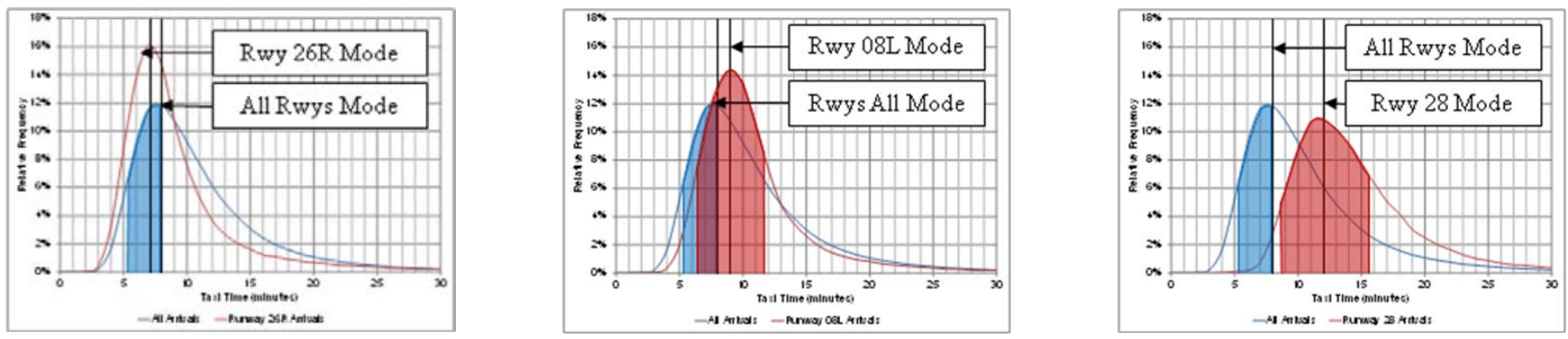

Figure 5. Underlying Distribution Variance

In the previous publication, we acknowledged that runway assignment introduced variation in taxi times that would be improper to consider noise. However, we resigned ourselves to ignoring runway assignment because runway data was not easily available. The ASPM dataset of flight records plans to incorporate runway data in the near future. Hence, we reassess the importance of including runway data in future analysis.

Table 1 summarizes how the overall taxi time distributions at ATL (all runways) compare with the distributions for the individual runways. The half- maximum region of the distribution of all ATL arrivals contains the mode of the distribution for arrivals on two runways. The half-maximum region of the distribution of all ATL departures contains the mode of the distribution for departures on six runways. As expected, including runway assignment in the aggregation factors reduces the variance of most of the taxi time distributions that fit in this category. The half-maximum regions of the distributions for arrivals on four runways and the half-maximum region for the overall distribution overlap. The half-maximum regions of the 
distributions for departures on one runway and the half-maximum region for the overall distribution overlap. The variance of most of these distributions is smaller than that of the overall distribution. We asserted that the higher-level distributions fitting in this category has a limited influence on the lowerlevel distribution. Hence, the variance of some distributions will decrease (compared to its lowerlevel counterpart) and others will not. The distributions for the far runways, Runway 10 and Runway 28, also behaved as expected. The mode of both runway distributions is about four-minutes greater than the mode of the airport distribution, and the half-maximum region for most taxi-in distributions is relatively small. Therefore, the halfmaximum region of the distributions for arrivals on the two far runways does not intersect the halfmaximum region for the overall distribution. The half-maximum region of the distributions for departures on the two far runways also does not intersect the half-maximum region for the overall distribution. Therefore, the taxi times for arrivals or departures using either of these runways do not influence the variance of the underlying distribution of the overall airport taxi times. The fact that the higher-level distribution variances increased or decreased is coincidental, since the lower-level and higher-level distributions are different.

Table 1. Runway Influence at ATL

\begin{tabular}{|c|c|c|c|c|c|c|}
\hline & \multicolumn{3}{|c|}{ Taxi-In } & \multicolumn{3}{c|}{ Taxi-Out } \\
\hline & $\begin{array}{c}\text { Variance } \\
\text { Increases }\end{array}$ & $\begin{array}{c}\text { Variance } \\
\text { Decreases }\end{array}$ & $\begin{array}{c}\text { Variance } \\
\text { Equal }\end{array}$ & $\begin{array}{c}\text { Variance } \\
\text { Increases }\end{array}$ & $\begin{array}{c}\text { Variance } \\
\text { Decreases }\end{array}$ & $\begin{array}{c}\text { Variance } \\
\text { Equal }\end{array}$ \\
\hline $\begin{array}{c}\text { Higher-Level Mode in } \\
\text { Lower-Level Half-Max } \\
\text { Region }\end{array}$ & 0 & 2 & 0 & 1 & 5 & 0 \\
\hline $\begin{array}{c}\text { Higher-Level and } \\
\text { Lower-Level Half-Max } \\
\text { Regions Overlap }\end{array}$ & 1 & 3 & 0 & 1 & 0 & 0 \\
\hline $\begin{array}{c}\text { Higher-Level and } \\
\text { Lower-Level Half-Max } \\
\text { Regions Separate }\end{array}$ & 2 & 0 & 0 & 1 & 1 & 0 \\
\hline
\end{tabular}

\section{Impact of Arrival and Departure Gate on Variance}

As identified in Tables 2, 3, and 4, adding carrier (both ticketing and operating), concourse and terminal, or gate to the aggregation factors produces results similar to those for the previous aggregation level. More often than not, if the mode of the higherlevel distribution is inside the half-maximum region of its respective lower-level distribution, then the variance of the higher-level distribution is smaller than the variance of the lower-level distribution. However, unlike adding runway, when the halfmaximum regions overlapped, adding the remaining aggregation factors mostly increased the variance of the new distribution.
The variance of eleven taxi-in distributions and twenty-five taxi-out distributions (aggregated by airport, runway, and carrier) did not change after adding concourse/terminal to the aggregation factors. For each of these instances, the half-maximum region of the lower-level distribution contains the mode of the higher-level distribution. In fact, the mode of the observed distributions also did not change. Additionally, for most instances, the number of observations generating the lower and higher level distributions also remained unchanged. For example, all American Airlines arrivals taxi to the North Terminal of Concourse T. Therefore, including concourse/terminal did not provide any additional information. 
Table 2. Carrier Influence at ATL

\begin{tabular}{|c|c|c|c|c|c|c|}
\hline & \multicolumn{3}{|c|}{ Taxi-In } & \multicolumn{3}{c|}{ Taxi-Out } \\
\hline & $\begin{array}{c}\text { Variance } \\
\text { Increases }\end{array}$ & $\begin{array}{c}\text { Variance } \\
\text { Decreases }\end{array}$ & $\begin{array}{c}\text { Variance } \\
\text { Equal }\end{array}$ & $\begin{array}{c}\text { Variance } \\
\text { Increases }\end{array}$ & $\begin{array}{c}\text { Variance } \\
\text { Decreases }\end{array}$ & $\begin{array}{c}\text { Variance } \\
\text { Equal }\end{array}$ \\
\hline $\begin{array}{c}\text { Higher-Level Mode in } \\
\text { Lower-Level Half-Max } \\
\text { Region }\end{array}$ & 7 & 16 & 0 & 4 & 27 & 0 \\
\hline $\begin{array}{c}\text { Higher-Level and } \\
\text { Lower-Level Half-Max } \\
\text { Regions Overlap }\end{array}$ & 9 & 1 & 0 & 13 & 5 & 0 \\
\hline $\begin{array}{c}\text { Higher-Level and } \\
\text { Lower-Level Half-Max } \\
\text { Regions Separate }\end{array}$ & 2 & 1 & 0 & 1 & 3 & 0 \\
\hline
\end{tabular}

Table 3. Concourse/Terminal Influence at ATL

\begin{tabular}{|c|c|c|c|c|c|c|}
\hline & \multicolumn{3}{|c|}{ Taxi-In } & \multicolumn{3}{c|}{ Taxi-Out } \\
\hline & $\begin{array}{c}\text { Variance } \\
\text { Increases }\end{array}$ & $\begin{array}{c}\text { Variance } \\
\text { Decreases }\end{array}$ & $\begin{array}{c}\text { Variance } \\
\text { Equal }\end{array}$ & $\begin{array}{c}\text { Variance } \\
\text { Increases }\end{array}$ & $\begin{array}{c}\text { Variance } \\
\text { Decreases }\end{array}$ & $\begin{array}{c}\text { Variance } \\
\text { Equal }\end{array}$ \\
\hline $\begin{array}{c}\text { Higher-Level Mode in } \\
\text { Lower-Level Half-Max } \\
\text { Region }\end{array}$ & 21 & 40 & 11 & 17 & 34 & 25 \\
\hline $\begin{array}{c}\text { Higher-Level and } \\
\text { Lower-Level Half-Max } \\
\text { Regions Overlap }\end{array}$ & 19 & 5 & 0 & 17 & 10 & 0 \\
\hline $\begin{array}{c}\text { Higher-Level and } \\
\text { Lower-Level Half-Max } \\
\text { Regions Separate }\end{array}$ & 13 & 1 & 0 & 3 & 1 & 0 \\
\hline
\end{tabular}

Table 4. Gate Influence at ATL

\begin{tabular}{|c|c|c|c|c|c|c|}
\hline & \multicolumn{3}{|c|}{ Taxi-In } & \multicolumn{3}{c|}{ Taxi-Out } \\
\hline & $\begin{array}{c}\text { Variance } \\
\text { Increases }\end{array}$ & $\begin{array}{c}\text { Variance } \\
\text { Decreases }\end{array}$ & $\begin{array}{c}\text { Variance } \\
\text { Equal }\end{array}$ & $\begin{array}{c}\text { Variance } \\
\text { Increases }\end{array}$ & $\begin{array}{c}\text { Variance } \\
\text { Decreases }\end{array}$ & $\begin{array}{c}\text { Variance } \\
\text { Equal }\end{array}$ \\
\hline $\begin{array}{c}\text { Higher-Level Mode in } \\
\text { Lower-Level Half-Max } \\
\text { Region }\end{array}$ & 95 & 311 & 0 & 31 & 244 & 1 \\
\hline $\begin{array}{c}\text { Higher-Level and } \\
\text { Lower-Level Half-Max } \\
\text { Regions Overlap }\end{array}$ & 111 & 12 & 0 & 126 & 53 & 0 \\
\hline $\begin{array}{c}\text { Higher-Level and } \\
\text { Lower-Level Half-Max } \\
\text { Regions Separate }\end{array}$ & 27 & 0 & 0 & 37 & 8 & 0 \\
\hline
\end{tabular}

Appendix I includes summary tables for JFK and ORD. We make similar observations about the results for JFK and ORD to the results for ATL. Runway assignment significantly influences both taxi-in and taxi-out times. Carrier, concourse/terminal, and gate also influence taxi times, but at progressively less significance than the previous aggregation factor. All of the taxi-in instances at JFK in which the lower-level halfmaximum region contained the mode of the higherlevel distribution were associated with JetBlue. For each of these, the standard deviations for both the 
lower and upper level distributions were less than one minute. Therefore, the variance increase may not be real, but due to interpolation when approximating the standard deviations.

\section{Factors Influencing Taxi Delay}

Since each of the factors discussed in the previous section influences taxi time variance, they also influence taxi delay. As illustrated in Figure 6, ATL experienced a significant and sustained increase in taxi-in delay beginning in June 2006. Prior to the increase in taxi-in delay, a new runway opened that is significantly farther from the airport terminal than the other airport runways. On May 27, 2006, Runway $10 / 28$ opened, which typically functions as an arrival runway during heavy arrival periods. Since its opening, Runway 10/28 has consistently served fifteen to twenty percent of ATL's arrivals. Neither the authors' methodology nor the ASPM methodology explicitly addresses runway assignment. The authors' methodology captures typical taxi times and the ASPM methodology captures minimum taxi times. Therefore, nominal values generated using both methods miss the influence of Runway 10/28.

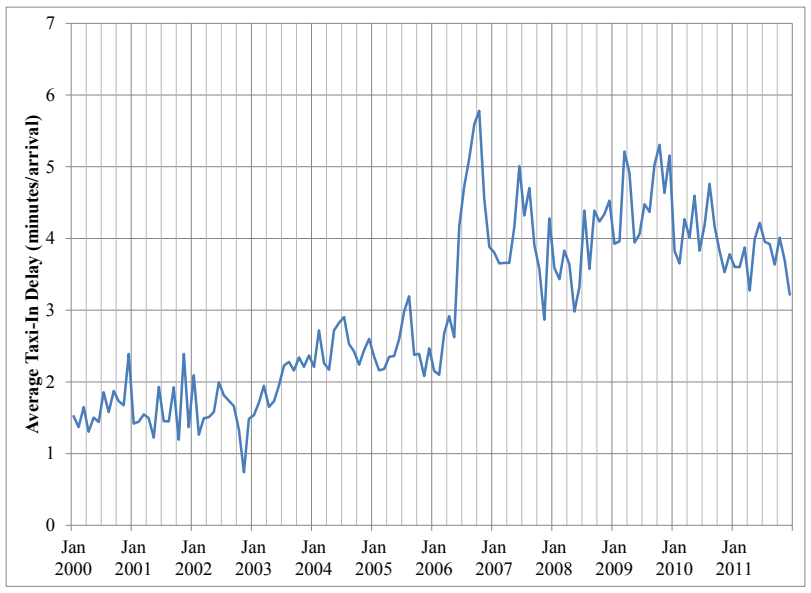

Figure 6. Taxi-In Delay at ATL

In the previous section, we compared the effect of different aggregation methods on taxi time. In this section, we investigate how some of those different aggregation methods influence taxi delay. Since both the ASPM methodology and our methodology ignore runway assignment and gate location, we focus on those aggregation methods that include them.

\section{Impact of Runway Assignment on Delay}

Figure 7 illustrates the FY 2011 average taxi-out delay for each of the Core 30 airports using the authors' methodology. The darker bars include runway assignment in the nominal values, whereas the lighter bars do not. Taxi-out delay at most airports $(70 \%)$ increased or decreased by less than 15 seconds. Taxi-out delay decreased by more than one minute at only one airport, New York La Guardia (LGA). Taxi-out delay increased by more than one minute at only one airport, Phoenix Sky Harbor International (PHX). Runway assignment data is not available for Honolulu International (HNL). Therefore, delay at HNL ignoring runway assignment and delay including runway assignment are the same.

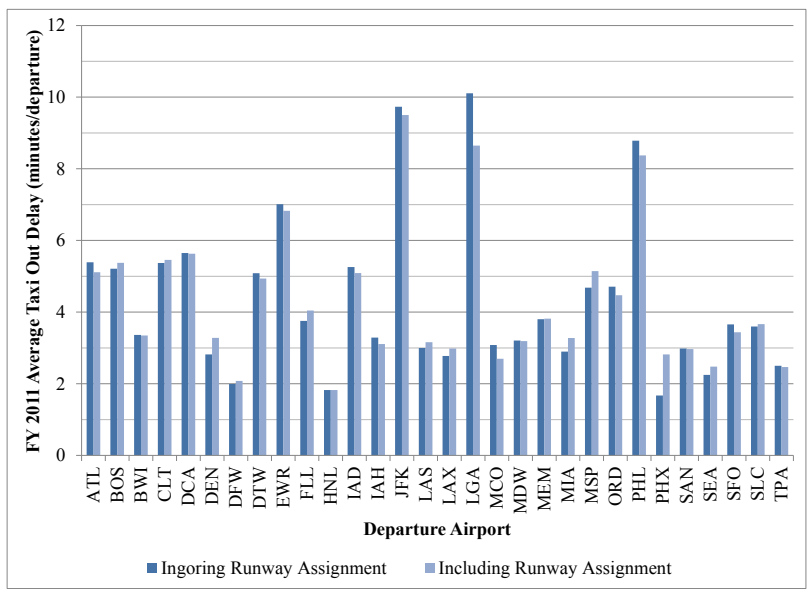

Figure 7. FY 2011 Average Taxi-Out Delay

Figure 8 shows weighted taxi-out distributions for LGA FY 2011 departures. The author's methodology generated a nominal taxi-out time of 15 minutes for the airport. If we include runway assignment in the determination of the nominal taxiout times, then we would generate 19 minutes for Runway 04, 17 minutes for Runway 13, and 15 minutes for Runway 31. Since more aircraft departed LGA using Runway 04 (31\%) and Runway 13 (39\%) than Runway 31 (25\%), delay calculations using nominal values that include runway assignment increases for most departures. Hence, average taxiout delay decreased. 


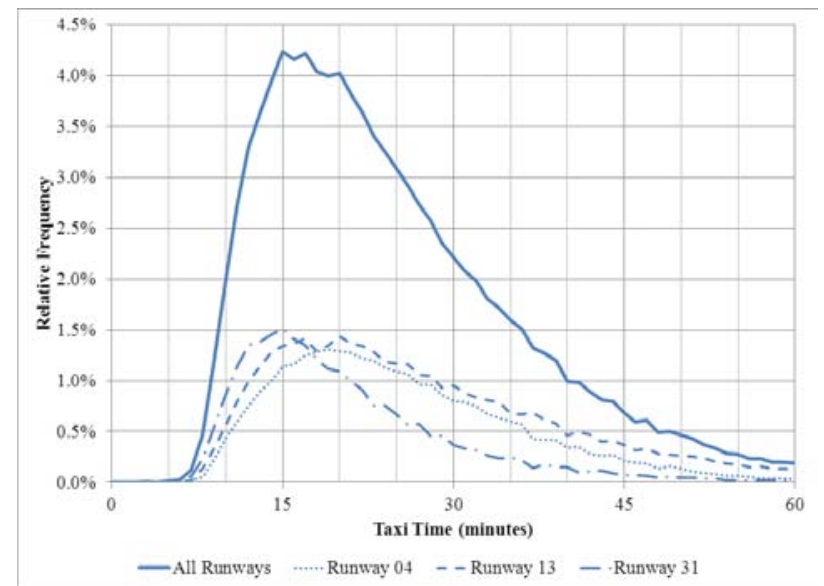

Figure 8. FY 2011 Taxi-Out at LGA

Figure 9 shows weighted taxi-out distributions for PHX FY 2011 departures. The author's methodology generated a nominal taxi-out time of 10 minutes for the airport. If we include runway assignment in the determination of the nominal taxiout times, then we would generate 10 minutes for Runway 07L and 6 minutes for Runway 25R. Departures using Runway 25R create a bimodal distribution. Aggregating the taxi times by carrier would give the distribution a single mode, since Southwest Airlines operated most aircraft with sixminute taxi-out times and US Airways ticketed most aircraft with ten-minute taxi-out times. Since including runway would decrease the nominal taxiout time for those departures using Runway 25R, average taxi-out delay increased for PHX.

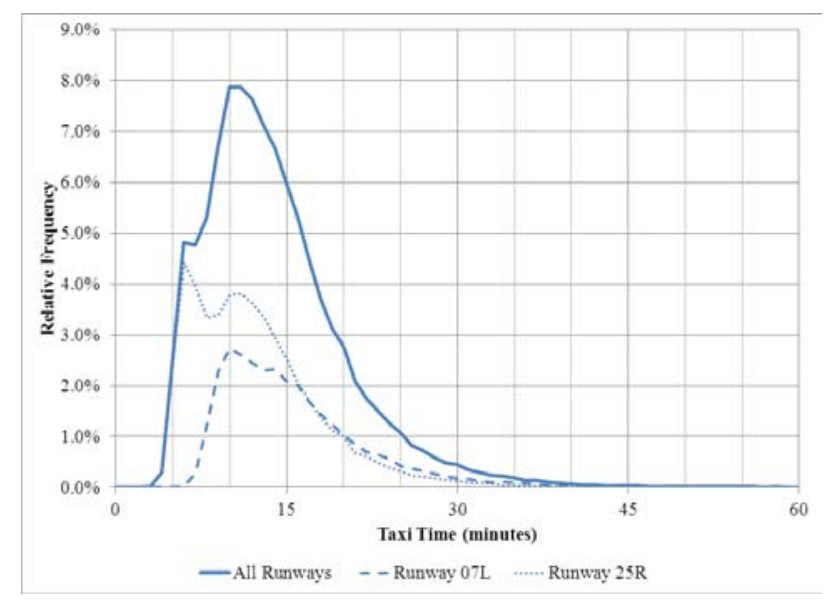

Figure 9. FY 2011 Taxi-Out at PHX

Figure 10 illustrates the FY 2011 average taxi-in delay for each of the Core 30 airports using the authors' methodology. Runway assignment appears to impact taxi-in delay more than taxi-out delay. Taxi-in delay changed by less than 15 seconds at about half of the Core 30 airports. However, taxi-in delay changed by less than $10 \%$ at about one-third of the Core 30 airports. Taxi-in delay decreased by more than one minute at Dallas/Fort Worth International (DFW), a 57\% decrease. Note that the airports with the largest delay differences are also some of the largest airports, geographically.

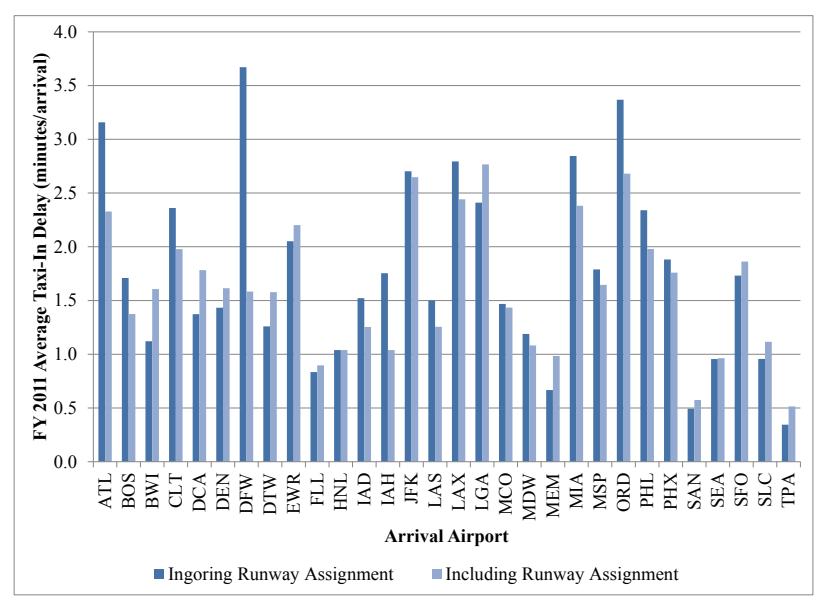

Figure 10. FY 2011 Average Taxi-In Delay

Figure 11 shows weighted taxi-in distributions for DFW FY 2011 arrivals. The author's methodology generated a nominal taxi-in time of five minutes for the airport. DFW arrivals create a bimodal distribution. If we include runway assignment in the determination of the nominal taxiin times, then we would generate five minutes for only Runways $17 \mathrm{C}, 18 \mathrm{R}, 35 \mathrm{C}$, and 36L. Nominal values for the three other frequently used arrival runways would be larger. The authors' methodology generated nine minutes for Runway $31 \mathrm{R}$, ten minutes for $13 \mathrm{R}$, and twelve minutes for Runway $17 \mathrm{~L}$. These three runways account for approximately $18 \%$ of the FY 2011 arrivals, decreasing the average taxi-in delay. 


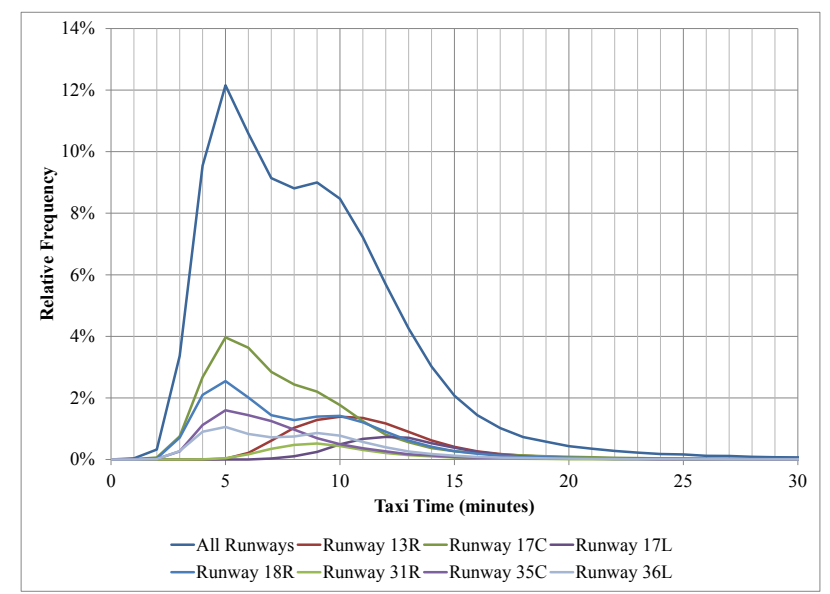

Figure 11. FY 2011 Taxi-In at DFW

\section{Impact of Arrival and Departure Gate on Delay}

Figure 12 shows the average FY 2011 taxi-out delay for ATL, JFK, and ORD using the authors' methodology. Figure 13 shows the average FY 2011 taxi-in delay. The blue bars include runway assignment in the aggregation level used to determine the nominal values. The red bars also include runway assignment, but adds the airport terminal and concourse. The green bars add the airport gate to the aggregation level. Each increase in aggregation level yields a minimal improvement in delay calculation. The best improvement results from the addition of gates at ATL. Compared to the runway level, including gates at ATL decreases the average taxi-out delay by the approximately 5\% (15 seconds) and increases the average taxi-in delay by approximately $8 \%$ (11 seconds).

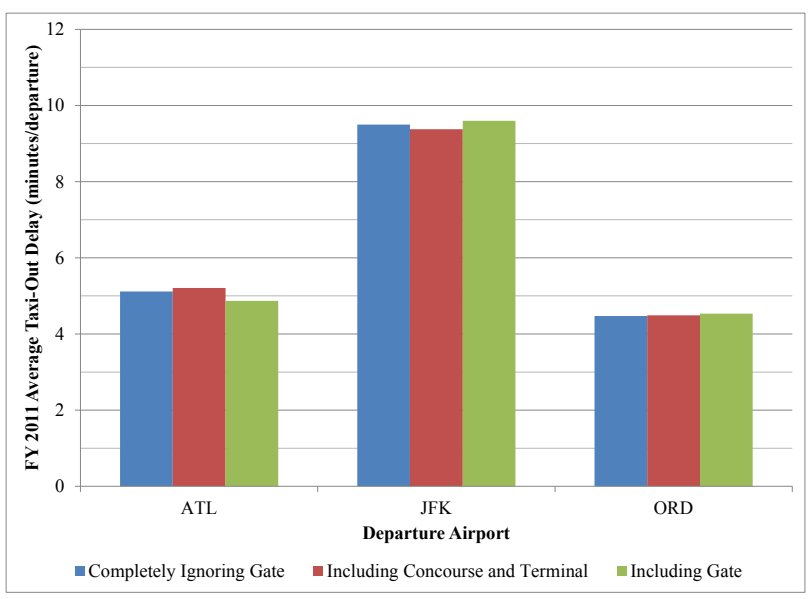

Figure 12. FY 2011 Average Taxi-Out Delay

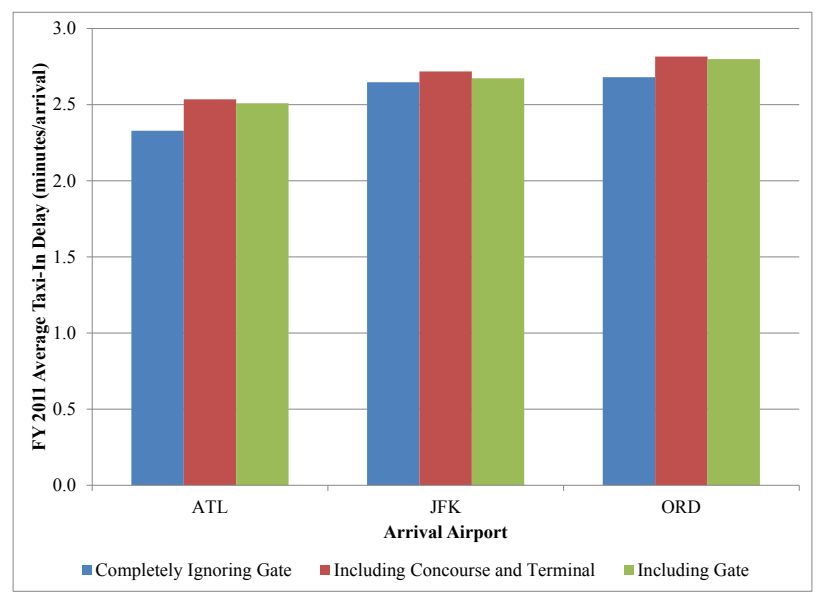

Figure 13. FY 2011 Average Taxi-In Delay

\section{Conclusions}

We used the simple methodology for characterizing aircraft taxi times developed by the authors in a previous paper. We tested the error produced due to a concession made in that paper concerning the influence of runway assignment on taxi time characterization. Runway assignment explains a significant portion of taxi time variation, and can translate into a misrepresentation of taxi delay. We also tested an implication made in the previous paper concerning airport gate location. The actual airport gate used explains some portion of taxi time variation, although a lesser amount than the runway used. However, using the actual airport gate provides minimal benefit to taxi delay calculations. Overall, knowing the aircraft carrier and the aircraft equipment type provide a sufficient airport location when characterizing taxi times.

\section{References}

[1] $112^{\text {th }}$ Congress, 2012, FAA Modernization and Reform Act of 2012, Public Law 112-95, 126 Stat. 11.

[2] Federal Aviation Administration, 2012, Destination 2025, Washington, DC (Online Document) http://www.faa.gov/about/plans_reports/media/Destin ation2025.pdf .

[3] Robinson, Derek P., Daniel J. Murphy, 2010, Aircraft Taxi Times at U.S. Domestic Airports, American Institute of Aeronautics and Astronautics 
Aviation Technology, Integration, and Operations Conference.

[4] Suissa, Anne, November 2010, Title 14 Code of Federal Regulations Part 234, DOT Research and Innovative Technology Administration, Bureau of Transportation Statistics, Technical Directive 20, Washington, DC.

[5] Kondo, Akira, 2009, The Derivation of the Unimpeded Taxi Times in the Estimation of the Taxi
Time Delay, FAA Office of Aviation Policy and Plans, Technical Note 1, Washington, DC.

\section{Integrated Communications Navigation} and Surveillance (ICNS) Conference April 23-25, 2013 


\section{Appendix I}

Table 5. Runway Influence at JFK

\begin{tabular}{|c|c|c|c|c|c|c|}
\hline & \multicolumn{3}{|c|}{ Taxi-In } & \multicolumn{3}{c|}{ Taxi-Out } \\
\hline & $\begin{array}{c}\text { Variance } \\
\text { Increases }\end{array}$ & $\begin{array}{c}\text { Variance } \\
\text { Decreases }\end{array}$ & $\begin{array}{c}\text { Variance } \\
\text { Equal }\end{array}$ & $\begin{array}{c}\text { Variance } \\
\text { Increases }\end{array}$ & $\begin{array}{c}\text { Variance } \\
\text { Decreases }\end{array}$ & $\begin{array}{c}\text { Variance } \\
\text { Equal }\end{array}$ \\
\hline $\begin{array}{c}\text { Higher-Level Mode in } \\
\text { Lower-Level Half-Max } \\
\text { Region }\end{array}$ & 0 & 6 & 0 & 3 & 0 & 0 \\
\hline $\begin{array}{c}\text { Higher-Level and } \\
\text { Lower-Level Half-Max } \\
\text { Regions Overlap }\end{array}$ & 0 & 2 & 0 & 2 & 0 & 0 \\
\hline $\begin{array}{c}\text { Higher-Level and } \\
\text { Lower-Level Half-Max } \\
\text { Regions Separate }\end{array}$ & 0 & 0 & 0 & 0 & 0 & 0 \\
\hline
\end{tabular}

Table 6. Carrier Influence at JFK

\begin{tabular}{|c|c|c|c|c|c|c|}
\hline & \multicolumn{3}{|c|}{ Taxi-In } & \multicolumn{3}{c|}{ Taxi-Out } \\
\hline & $\begin{array}{c}\text { Variance } \\
\text { Increases }\end{array}$ & $\begin{array}{c}\text { Variance } \\
\text { Decreases }\end{array}$ & $\begin{array}{c}\text { Variance } \\
\text { Equal }\end{array}$ & $\begin{array}{c}\text { Variance } \\
\text { Increases }\end{array}$ & $\begin{array}{c}\text { Variance } \\
\text { Decreases }\end{array}$ & $\begin{array}{c}\text { Variance } \\
\text { Equal }\end{array}$ \\
\hline $\begin{array}{c}\text { Higher-Level Mode in } \\
\text { Lower-Level Half-Max } \\
\text { Region }\end{array}$ & 4 & 11 & 0 & 4 & 12 & 0 \\
\hline $\begin{array}{c}\text { Higher-Level and } \\
\text { Lower-Level Half-Max } \\
\text { Regions Overlap }\end{array}$ & 4 & 4 & 0 & 7 & 4 & 0 \\
\hline $\begin{array}{c}\text { Higher-Level and } \\
\text { Lower-Level Half-Max } \\
\text { Regions Separate }\end{array}$ & 15 & 8 & 0 & 2 & 1 & 0 \\
\hline
\end{tabular}

Table 7. Concourse/Terminal Influence at JFK

\begin{tabular}{|c|c|c|c|c|c|c|}
\hline & \multicolumn{3}{|c|}{ Taxi-In } & \multicolumn{3}{c|}{ Taxi-Out } \\
\hline & $\begin{array}{c}\text { Variance } \\
\text { Increases }\end{array}$ & $\begin{array}{c}\text { Variance } \\
\text { Decreases }\end{array}$ & $\begin{array}{c}\text { Variance } \\
\text { Equal }\end{array}$ & $\begin{array}{c}\text { Variance } \\
\text { Increases }\end{array}$ & $\begin{array}{c}\text { Variance } \\
\text { Decreases }\end{array}$ & $\begin{array}{c}\text { Variance } \\
\text { Equal }\end{array}$ \\
\hline $\begin{array}{c}\text { Higher-Level Mode in } \\
\text { Lower-Level Half-Max } \\
\text { Region }\end{array}$ & 4 & 9 & 27 & 3 & 7 & 18 \\
\hline $\begin{array}{c}\text { Higher-Level and } \\
\text { Lower-Level Half-Max } \\
\text { Regions Overlap }\end{array}$ & 2 & 1 & 0 & 3 & 1 & 0 \\
\hline $\begin{array}{c}\text { Higher-Level and } \\
\text { Lower-Level Half-Max } \\
\text { Regions Separate }\end{array}$ & 1 & 0 & 0 & 1 & 0 & 0 \\
\hline
\end{tabular}


Table 8. Gate Influence at JFK

\begin{tabular}{|c|c|c|c|c|c|c|}
\hline & \multicolumn{3}{|c|}{ Taxi-In } & \multicolumn{3}{c|}{ Taxi-Out } \\
\hline & $\begin{array}{c}\text { Variance } \\
\text { Increases }\end{array}$ & $\begin{array}{c}\text { Variance } \\
\text { Decreases }\end{array}$ & $\begin{array}{c}\text { Variance } \\
\text { Equal }\end{array}$ & $\begin{array}{c}\text { Variance } \\
\text { Increases }\end{array}$ & $\begin{array}{c}\text { Variance } \\
\text { Decreases }\end{array}$ & $\begin{array}{c}\text { Variance } \\
\text { Equal }\end{array}$ \\
\hline $\begin{array}{c}\text { Higher-Level Mode in } \\
\text { Lower-Level Half-Max } \\
\text { Region }\end{array}$ & 0 & 0 & 0 & 0 & 0 & 0 \\
\hline $\begin{array}{c}\text { Higher-Level and } \\
\text { Lower-Level Half-Max } \\
\text { Regions Overlap }\end{array}$ & 0 & 0 & 0 & 0 & 0 & 0 \\
\hline $\begin{array}{c}\text { Higher-Level and } \\
\text { Lower-Level Half-Max } \\
\text { Regions Separate }\end{array}$ & 96 & 0 & 0 & 100 & 0 & 0 \\
\hline
\end{tabular}

Table 9. Runway Influence at ORD

\begin{tabular}{|c|c|c|c|c|c|c|}
\hline & \multicolumn{3}{|c|}{ Taxi-In } & \multicolumn{3}{c|}{ Taxi-Out } \\
\hline & $\begin{array}{c}\text { Variance } \\
\text { Increases }\end{array}$ & $\begin{array}{c}\text { Variance } \\
\text { Decreases }\end{array}$ & $\begin{array}{c}\text { Variance } \\
\text { Equal }\end{array}$ & $\begin{array}{c}\text { Variance } \\
\text { Increases }\end{array}$ & $\begin{array}{c}\text { Variance } \\
\text { Decreases }\end{array}$ & $\begin{array}{c}\text { Variance } \\
\text { Equal }\end{array}$ \\
\hline $\begin{array}{c}\text { Higher-Level Mode in } \\
\text { Lower-Level Half-Max } \\
\text { Region }\end{array}$ & 2 & 5 & 0 & 1 & 3 & 0 \\
\hline $\begin{array}{c}\text { Higher-Level and } \\
\text { Lower-Level Half-Max } \\
\text { Regions Overlap }\end{array}$ & 2 & 0 & 0 & 6 & 0 & 0 \\
\hline $\begin{array}{c}\text { Higher-Level and } \\
\text { Lower-Level Half-Max } \\
\text { Regions Separate }\end{array}$ & 1 & 1 & 0 & 2 & 0 & 0 \\
\hline
\end{tabular}

Table 10. Carrier Influence at ORD

\begin{tabular}{|c|c|c|c|c|c|c|}
\hline & \multicolumn{3}{|c|}{ Taxi-In } & \multicolumn{3}{c|}{ Taxi-Out } \\
\hline & $\begin{array}{c}\text { Variance } \\
\text { Increases }\end{array}$ & $\begin{array}{c}\text { Variance } \\
\text { Decreases }\end{array}$ & $\begin{array}{c}\text { Variance } \\
\text { Equal }\end{array}$ & $\begin{array}{c}\text { Variance } \\
\text { Increases }\end{array}$ & $\begin{array}{c}\text { Variance } \\
\text { Decreases }\end{array}$ & $\begin{array}{c}\text { Variance } \\
\text { Equal }\end{array}$ \\
\hline $\begin{array}{c}\text { Higher-Level Mode in } \\
\text { Lower-Level Half-Max } \\
\text { Region }\end{array}$ & 10 & 40 & 0 & 7 & 21 & 0 \\
\hline $\begin{array}{c}\text { Higher-Level and } \\
\text { Lower-Level Half-Max } \\
\text { Regions Overlap }\end{array}$ & 12 & 16 & 0 & 22 & 10 & 0 \\
\hline $\begin{array}{c}\text { Higher-Level and } \\
\text { Lower-Level Half-Max } \\
\text { Regions Separate }\end{array}$ & 5 & 7 & 0 & 5 & 3 & 0 \\
\hline
\end{tabular}


Table 11. Concourse/Terminal Influence at ORD

\begin{tabular}{|c|c|c|c|c|c|c|}
\hline & \multicolumn{3}{|c|}{ Taxi-In } & \multicolumn{3}{c|}{ Taxi-Out } \\
\hline & $\begin{array}{c}\text { Variance } \\
\text { Increases }\end{array}$ & $\begin{array}{c}\text { Variance } \\
\text { Decreases }\end{array}$ & $\begin{array}{c}\text { Variance } \\
\text { Equal }\end{array}$ & $\begin{array}{c}\text { Variance } \\
\text { Increases }\end{array}$ & $\begin{array}{c}\text { Variance } \\
\text { Decreases }\end{array}$ & $\begin{array}{c}\text { Variance } \\
\text { Equal }\end{array}$ \\
\hline $\begin{array}{c}\text { Higher-Level Mode in } \\
\text { Lower-Level Half-Max } \\
\text { Region }\end{array}$ & 41 & 52 & 21 & 27 & 41 & 13 \\
\hline $\begin{array}{c}\text { Higher-Level and } \\
\text { Lower-Level Half-Max } \\
\text { Regions Overlap }\end{array}$ & 12 & 0 & 0 & 9 & 6 & 0 \\
\hline $\begin{array}{c}\text { Higher-Level and } \\
\text { Lower-Level Half-Max } \\
\text { Regions Separate }\end{array}$ & 4 & 0 & 0 & 3 & 0 & 0 \\
\hline
\end{tabular}

Table 12. Gate Influence at ORD

\begin{tabular}{|c|c|c|c|c|c|c|}
\hline & \multicolumn{3}{|c|}{ Taxi-In } & \multicolumn{3}{c|}{ Taxi-Out } \\
\hline & $\begin{array}{c}\text { Variance } \\
\text { Increases }\end{array}$ & $\begin{array}{c}\text { Variance } \\
\text { Decreases }\end{array}$ & $\begin{array}{c}\text { Variance } \\
\text { Equal }\end{array}$ & $\begin{array}{c}\text { Variance } \\
\text { Increases }\end{array}$ & $\begin{array}{c}\text { Variance } \\
\text { Decreases }\end{array}$ & $\begin{array}{c}\text { Variance } \\
\text { Equal }\end{array}$ \\
\hline $\begin{array}{c}\text { Higher-Level Mode in } \\
\text { Lower-Level Half-Max } \\
\text { Region }\end{array}$ & 100 & 224 & 5 & 27 & 226 & 5 \\
\hline $\begin{array}{c}\text { Higher-Level and } \\
\text { Lower-Level Half-Max } \\
\text { Regions Overlap }\end{array}$ & 50 & 8 & 0 & 57 & 8 & 0 \\
\hline $\begin{array}{c}\text { Higher-Level and } \\
\text { Lower-Level Half-Max } \\
\text { Regions Separate }\end{array}$ & 13 & 1 & 0 & 18 & 0 & 0 \\
\hline
\end{tabular}

2013 Integrated Communications Navigation and Surveillance (ICNS) Conference April 23-25, 2013 